\title{
THỰC TRẠNG NGUỒN NHÂN LỰC VÀ NHU CẦU ĐÀO TẠO TRONG LĨNH VỰC KHÍ TƯợNG THỦY VĂN
}

\section{Trần Hồng Thái ${ }^{1}$}

Tóm tắt: Ngành khi tương thủy văn (KTTV) đã và đang được tăng cuờng đầu tu nhằm hướng tới muc tiêu đạt trình độ của các nước tiên tiến trong khu vực Châu Á; phấn đấu đến năm 2025 2030 có hệ thống quan trắc hoàn chỉnh, tuoong đurong các nước tiên tiến trong khu vưc; công nghệ dư báo và hệ thống thông tin chuyên ngành được đà̀u tu chiều sâu vói các bản tin dụ báo KTTV có chất lượng cao, hướng tới dụ báo, cảnh báo tác động, đáp ứng yêu cầu của xã họi, góp phần đảm bảo tăng trương bền vũng của đất nước và giám sát biến đổi khi hậu. Tổng cuc KTTV coi nguồn nhân lực chất lượng cao là chì khóa thành công của sự nghiệp hiện đại hóa và tụ động hóa ngành KTTV, là cơ sở để hoàn thành các mục tiêu của Chiến luợc phát triển ngành KTTV đến năm 2030 và Chiến lược Quốc gia về biến đổi khí hậu và sẽ tiếp tục thực hiện các chủ truơng nhất quán để đạt được các muc tiêu chiến lược đã đề ra.

Từ khóa: Nguồn nhân lục, nhân lục chất lượng cao, chiến lược.

Ban Biên tập nhận bài: 11/12/2019 Ngày phản biện xong: 12/12/2019 Ngày đăng bài: 20/12/2019

\section{Mở đầu}

Cùng với sự phát triển nhanh của khoa học và công nghệ hiện đại, khoa học công nghệ trong lĩnh vực KTTV ở Việt Nam cũng đã từng bước được nâng cấp, cải tiến. Công nghệ đo đạc được đầu tư tự động hoá, công nghệ dự báo số trị đã triển khai trong dự báo nghiệp vụ,... Để ứng dụng và làm chủ được các công nghệ tiên tiến hiện nay, nguồn nhân lực của ngành KTTV cũng cần được phát triển tương xứng, đặc biệt là nhân lực chất lượng cao.

Có rất nhiều quan niệm khác nhau về nguồn nhân lực chất lượng cao, thể hiện trong khá nhiều nghiên cứu trong và ngoài nước. Theo Phó Giáo sư Đàm Đức Vượng, thì "Xây dựng nhân lực chất lượng cao có nghĩa là xây dựng đội ngũ nhân lực khoa học và công nghệ, nhất là các chuyên gia, tổng công trình sư, kỹ sư đầu ngành, công nhân có tay nghề cao, có trình độ chuyên môn-kỹ thuật tương đương với các nước tiên tiến trong khu vực, có đủ năng lực nghiên cứu, tiếp nhận, chuyển giao và đề xuất những giải pháp khoa học, công nghệ, kỹ thuật, giải quyết những vấn đề cơ bản của sự nghiệp công nghiệp hóa, hiện đại hóa đất nước; xây dựng hệ thống các cơ sở đào tạo nhân lực tiên tiến, hiện đại, đa dạng, cơ cấu ngành nghề đồng bộ; xây dựng sự nghiệp giáo dục tiên tiến, hiện đại và một xã hội học tập toàn diện để tạo nguồn nhân lực chất lượng cao". Theo một số nghiên cứu thì "Nhân lực chất lượng cao trước hết phải được thừa nhận trên thực tế, không phải ở dạng tiềm năng. Điều đó có nghĩa là nó không đồng nghĩa với học vị cao. Nhân lực chất lượng cao là những người có năng lực thực tế hoàn thành nhiệm vụ được giao một cách xuất sắc nhất, sáng tạo và có đóng góp thực sự hữu ích cho công việc của xã hội’'[1,2]. Những phẩm chất nhân cách của con người mới là yếu tố cơ bảo đảm chất lượng nguồn nhân lực. Sự phát triển nguồn nhân lực chất lượng cao tùy thuộc vào trình độ phát triển nhân cách tạo thành những bộ phận hợp thành cấu trúc nguồn nhân lực. Do vậy, giáo dục nhân cách phải được thực hiện trong bất cứ quá trình nào của chiến lược phát triển nguồn nhân lực. Những suy thoái nhân cách bao giờ cũng làm tổn thương đến sự 
phát triển nguồn nhân lực (một tập đoàn doanh nghiệp có thể phá sản nhiều khi chỉ do một nhóm cán bộ lãnh đạo sa vào tình trạng tham nhũng). Nguồn lực đó là người lao động có trí tuệ cao, có tay nghề thành thạo, có phẩm chất tốt đẹp được đào tạo bồi dưỡng và phát huy bởi một nền giáo dục tiên tiến gắn liền với một nền khoa học công nghệ hiện đại [2].

Nhận thức rõ vai trò của nguồn nhân lực đối với yêu cầu đẩy mạnh công nghiệp hóa, hiện đại hóa và hội nhập quốc tế, tại Đại hội đại biểu toàn quốc lần thứ VIII (1996), Đảng ta đã đề ra quan điểm [3]: "Lấy việc phát huy nguồn lực con người làm yếu tố cơ bản cho sự phát triển nhanh và bền vững", và "nâng cao dân trí, bồi dưỡng và phát huy nguồn lực to lớn của con người Việt Nam là nhân tố quyết định thắng lợi của công cuộc công nghiệp hóa, hiện đại hóa". Theo đánh giá của Ngân hàng Thế giới (WB), Việt Nam đang rất thiếu lao động có trình độ tay nghề, công nhân kỹ thuật bậc cao và chất lượng nguồn nhân lực Việt Nam cũng thấp hơn so với nhiều nước khác [5].

Trong chiến lược phát triển chung về nguồn nhân lực chất lượng cao của cả nước, ngành KTTV, mà đơn vị nòng cốt, tập trung là Tổng cục Khí tượng Thủy văn [6], cũng đã có chiến lược và chính sách cụ thể để phát triển nguồn nhân lực chất lượng cao của mình [7] và cũng đã đạt được những thành tựu nhất định. Tuy nhiên, với những yêu cầu, mục tiêu phát triển mới, việc nâng cao chất lượng nguồn nhân lực chất lượng cao ở ngành KTTV vẫn tiếp tục đặt ra như một nhu cầu tất yếu, cấp bách.

\section{Thực trạng nguồn nhân lực ngành tại} Tổng cục Khí tượng Thủy văn

Theo báo cáo đánh giá mới nhất [8], Tổng cục KTTV có 2558 cán bộ kĩ thuật gồm 03 nhóm: 1898 quan trắc viên, 120 cán bộ công nghệ thông tin và truyền thông, 540 dự báo viên. Số lượng cán bộ có bằng sau đại học chỉ chiếm $3 \%, 32 \%$ cán bộ tốt nghiệp đại học, $18 \%$ tốt nghiệp cao đẳng, 37\% tốt nghiệp trung cấp chuyên nghiệp và $10 \%$ có trình độ khác.
Số cán bộ kĩ thuật tại các đơn vị trung ương là 233, gồm 52 thạc sĩ (22.3\%) và 167 cử nhân (71.7\%). Trung tâm dự báo khí tượng thủy văn quốc gia sở hữu những nhân viên chất lượng cao nhất gồm $32.5 \%$ thạc sĩ và $61.5 \%$ cử nhân/kĩ sư.

Số cán bộ kĩ thuật tại 9 đài khu vực là 2325 , chiếm $87,4 \%$ tổng số cán bộ kỹ thuật của Tổng cục KTTV, trong đó $1 \%$ có bằng sau đại học, $27 \%$ tốt nghiệp đại học, $20 \%$ tốt nghiệp cao đẳng, $42 \%$ tốt nghiệp trường trung cấp chuyên nghiệp và $10 \%$ có trình độ khác. Tại các đài khu vực Đông Bắc và Tây Nguyên không có cán bộ có trình độ sau đại học, số cán bộ tốt nghiệp trường trung cấp chuyên nghiệp chiếm ưu thế (44,3\% ở Tây Bắc và 36,7\% tại Đài khu vực Tây Nguyên).

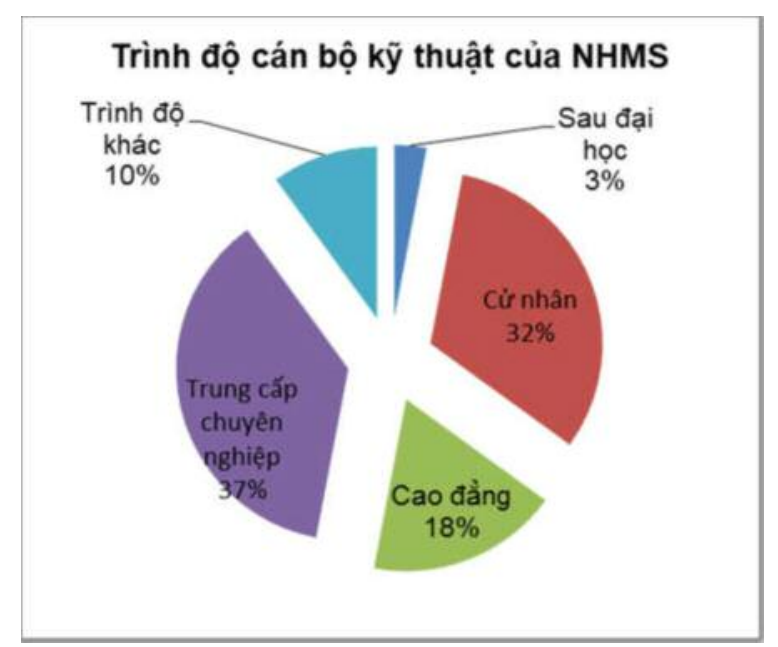

Hình 1. Trình độ học vấn các cán bộ Tổng cuc Khí tuợng Thủy văn

Trong số 540 cán bộ làm việc trong lĩnh vực dự báo và cảnh báo có 445 cán bộ tốt nghiệp đại học và sau đại học chiếm $83 \%$, còn lại $10 \%$ tốt nghiệp cao đẳng và $7 \%$ tốt nghiệp từ các trường trung cấp chuyên nghiệp. Đây là nhóm cán bộ được đào tạo bài bản hơn so với các nhóm khác, có khả năng hoàn thành tương đối tốt các nhiệm vụ được giao.

Tại Trung tâm Dự báo khí tượng thủy văn quốc gia, cơ quan đầu não chịu trách nhiệm cung cấp bản tin dự báo, cảnh báo thiên tai có 97 cán bộ trực tiếp chịu trách nhiệm dự báo và cảnh báo sớm, trong đó 96 cán bộ tốt nghiệp đại học và sau đại học. Đây là nhóm cán bộ đã, đang được 


\section{BÀI BÁO KHOA HỌC}

chú trọng đào tạo nhất, họ cũng đồng thời là đội ngũ cán bộ có nền tảng ngoại ngữ tốt nhất, thường xuyên làm việc với các đối tác nước ngoài nhất tại Tổng cục KTTV.

Tuy nhiên, vẫn có một số vấn đề tồn tại với nhóm cán bộ này như sau:

- Các dự báo viên không có nền tảng đào tạo đồng bộ (phần lớn tốt nghiệp từ các khóa đào tạo tại chức hoặc các khóa đào tạo chuyên ngành ngắn hạn);

- Khả năng tiếp cận các sản phẩm mô hình dự báo số trị (NWP) của các dự báo viên còn hạn chế do thiếu các công cụ dự báo hiện đại, hiển thị dữ liệu, chuẩn bị thông tin và quản lý dữ liệu và hệ thống phân phối;

- Các dự báo viên ở cấp tỉnh vẫn chưa đủ khả năng ứng dụng NWP một cách thuần thục và hiệu quả. Các phương pháp dự báo được sử dụng quá đơn giản và lỗi thời. Dự báo được thực hiện dựa trên các quan trắc và kinh nghiệm của các dự báo viên, rất ít sử dụng đến các mô hình dự báo hiện đại. Hạn chế về khả năng ngoại ngữ và tin học là một trở ngại để họ làm quen với các mô hình và công nghệ mới.

\section{Nhu cầu đào tạo đối với nguồn nhân lực của Tổng cục KTTV trong thời gian tới}

Cùng với quá trình tự động hóa, sẽ có một bộ phận lớn các quan trắc viên được điều chuyển tù̀ các trạm KTTV về các Đài KTTV tỉnh làm nhiệm vụ quản lý mang lưới trạm KTTV, trong đó có việc theo dõi, vận hành các trạm KTTV tự động, sẵn sàng sửa chữa, thay thế linh kiện của trạm trong trường hợp có hỏng hóc nhỏ. Như vậy đội ngũ quan trắc viên phải được đào tạo, bồi dưỡng lại để nâng cao năng lực công tác, làm chủ thiết bị, công nghệ, đáp ứng yêu cầu hiện đại hóa ngành.

Để đáp ứng yêu cầu tiếp thu công nghệ dự báo hiện đại mà trọng tâm là sử dụng các mô hình dự báo số trị có độ phân giải cao (với độ phân giải theo ô lưới từ dưới $5 \mathrm{~km}$, thậm chí có thể tới $1 \mathrm{~km}$ ) để dự báo các yếu tố thời tiết, dự báo bão và áp thấp nhiệt đới, dự báo sóng biển và nước biển dâng phục vụ sự phát triển kinh tế xã hội ngày càng cao của đất nước nhờ vào việc khai thác hiệu quả và nâng cấp hệ thống "siêu máy tính" cùng với các công nghệ dự báo hiện đại. Do đó cần phải tập trung đào tạo đội ngũ kỹ thuật viên có trình độ cao để vận hành tối ưu hệ thống tính toán. Ngoài ra, cần tập trung đào tạo, đào tạo lại và đào tại tại các cơ sở nước ngoài cho các dự báo viên vì đây chính là lực lượng trực tiếp sử dụng các sản phẩm dự báo hiện đại, các dự báo viên cần hiểu và khai thác đúng đắn, hiệu quả các nguồn số liệu quan trắc, dự báo từ mô hình số, radar, vệ tinh... để đưa ra những dự báo có chất lượng cao. Dự báo viên cũng cần có hiểu biết về các vấn đề kinh tế, xã hội, các thông tin về các đối tượng chịu tác động của thời tiết và thiên tai để có để đưa ra những cảnh báo về tác động của thời tiết và thiên tai đối với đời sống, nâng cao hiệu quả của các thông tin cảnh báo trong bảo vệ tính mạng, an toàn xã hội và góp phần vào quá trình phát triển bền vững của đất nước. Bên cạnh với việc phát triển nguồn nhân lực quan trắc viên, dự báo viên, kỹ thuật viên chất lượng cao nói trên, ngành KTTV cũng cần quan tâm đến việc phát triển nguồn nhân lực phục vụ công tác quản lý, truyền thông và dịch vụ KTTV để quảng bá và mang thông tin KTTV đến mọi tầng lớp xã hội, mọi ngành kinh tế đất nước, tạo động lực phát triển ngành KTTV.

Trong những năm qua, Tổng cục KTTV đã đẩy mạnh công tác đào tạo, bồi dưỡng cán bộ, chỉ tính riêng năm 2019, Tổng cục đã cử gần 1.000 lượt công chức, viên chức và người lao động đi học tập nâng cao trình độ dài hạn, khóa học ngắn hạn, bồi dưỡng kiến thức kinh tế-kỹ thuật ngạch chính, cao cấp ngành tài nguyên và môi trường ở trong nước và hàng chục viên chức đào tạo ngắn và dài hạn ở nước ngoài, tại các nước tiên tiến như Nhật Bản, Phần Lan.

\section{4. Đề xuất giải pháp đổi mới công tác đào tạo nguồn nhân lực KTTV}

Cung cấp nhân sự ở trình độ Đại học và sau đại học cho ngành Khí tượng Thủy văn hiện tại trong nước có các cơ sở đào tạo với quy mô lớn như Đại học Khoa học Tự nhiên, Đại học Thủy 
lợi, Đại học Tài nguyên và Môi trường Hà Nội, Đại học Tài nguyên và Môi trường thành phố Hồ Chí Minh, Đại học Bách Khoa thành phố Hồ Chí Minh, Đại học Cần Thơ, Viện Khoa học Khí tượng Thủy văn và Biến đổi khí hậu. Hàng năm, các cơ sở đào tạo cung cấp cho xã hội khoảng 50-70 cử nhân ngành Khí tượng và khoảng 80200 cử nhân/kỹ sư ngành Thủy văn. Hướng đào tạo của các trường bao gồm cả hai hướng ứng dụng và nghiên cứu khoa học cơ bản, tuy nhiên thực tế cho thấy cơ sở vật chất của ngành đào tạo Khí tượng Thủy văn được đầu tư rất hạn chế. Trong số các cơ sở đào tạo, khó có thể tìm được một phòng thí nghiệm đạt chuẩn quốc gia nào để phục vụ sinh viên. Các trang thiết bị thí nghiệm đo đạc hiện trường, thực hành có được trang bị nhưng không đồng bộ, thường xuyên. Đội ngũ giảng viên cũng còn hạn chế về số lượng, có khoảng cách giữa lớp các cán bộ sắp về hưu và lực lượng trẻ kế cận. Để đáp nâng cao chất lượng nguồn nhân lực nhằm đáp ứng các mục tiêu chiến lược của ngành KTTV, một số giải pháp đổi mới về công tác đào tạo xem xét được đưa ra gồm:

\subsection{Về hình thức đào tạo}

Đào tạo cán bộ kĩ thuật nên được triển khai dưới nhiều hình thức đào tạo để hoàn thành các mục tiêu chung của công tác xây dựng năng lực nhân sự khí tượng thủy văn và để chuẩn bị đối mặt với những thách thức mới. Mỗi hình thức đào tạo có nhóm đối tượng và chủ đề đào tạo riêng như sau:

Đào tạo nâng cao (tiến sĩ, thạc sĩ): Uu tiên các cán bộ khí tượng thủy văn phụ trách nghiên cứu khoa học, giáo dục và đào tạo, và hoạch định chính sách. Các chủ đề nghiên cứu sau nên được xem xét: quản lý dữ liệu, an toàn/an ninh thông tin, thiết bị tính toán hiệu năng cao, các phần mềm chuyên dụng, các mô hình dự báo hải dương, thiết bị viễn thám, vệ tinh khí tượng thủy văn, ra đa khí tượng thủy văn, tích hợp giữa khí tượng thủy văn và biến đổi khí hậu, sử dụng đất, giảm thiểu thiên tai, môi trường. Những cán bộ có năng lực có thể được cử đi học tại các Viện nghiên cứu hàn lâm, các trường đại học trong nước và nước ngoài;

Đào tạo tại chức: Loại hình đào tạo này dành cho các cán bộ kĩ thuật cần nâng cao trình độ học vấn cơ bản. Học viên có thể học bằng nhiều cách như đào tạo chính qui, học từ xa hoặc học trực tuyến. Với những khóa học này một số chủ đề như khí tượng thủy văn nông nghiệp, ra đa, biến đổi khí hậu, các thiết bị đo tự động khí tượng thủy văn, ngoại ngữ nên được tích hợp linh hoạt vào các chương trình của các cơ sở đào tạo (cao đẳng, đại học). Hiện tại, một số cơ sở đào tạo trong nước đang quan tâm hơn đến việc đổi mới chương trình giảng dạy và các tài liệu giảng dạy để đáp ứng yêu cầu tăng cường năng lực cho đội ngũ cán bộ khí tượng thủy văn;

Đào tạo bổ sung kĩ thuật và ngoài kĩ thuật: Các nội dung đào tạo nên được phát triển dựa trên nhu cầu đào tạo của cán bộ kĩ thuật để cung cấp kiến thức và kĩ năng cập nhật và để thích nghi với những thay đổi của hệ thống khí tượng thủy văn trong tương lai gần. Các khóa đào tạo bổ sung thường xuyên có thể được điều chỉnh để đáp ứng yêu cầu của cán bộ kĩ thuật tại các cấp.

Đào tạo trục tuyến: Một số khóa đào tạo tại chức hoặc các khóa đào tạo bổ sung (ví dụ khóa học tiếng Anh, khóa học về bảo trì, xử lý sự cố và sửa chữa những lỗi thiết bị nhỏ) nên được thiết kế theo hình thức trực tuyến (online). Những khóa học này sẽ hỗ trợ các cán bộ kĩ thuật tự học đặc biệt là các cán bộ ở các đài, trạm cấp tỉnh.

\subsection{Về chuơng trình, học liệu đào tạo}

Chuoong trình đào tạo: Chương trình đào tạo phải được phát triển phù hợp với các nhóm mục tiêu và tập trung vào cả lý thuyết và thực hành (tập trung nhiều hơn vào thực hành). Nội dung đào tạo nên được cập nhật với các xu hướng phát triển công nghệ mới trong ngành khí tượng thủy văn. Đồng thời, nên được thiết kế để cung cấp cho những người tham gia những chính sách, quy định mới, kinh nghiệm quốc tế và các vấn đề quản lý và lãnh đạo (giao tiếp, làm việc nhóm, ngoại ngữ) liên quan đến tăng cường năng lực 
nguồn nhân lực khí tượng thủy văn.

Học liệu đào tạo: Tất cả các hoạt động đào tạo cần có hỗ trợ từ những tài liệu tham khảo. Nội dung đào tạo cần được điều chỉnh phù hợp cho từng nhóm mục tiêu và được hỗ trợ bởi các biểu đồ, sơ đồ và tranh ảnh phù hợp. Các hướng dẫn, tài liệu học tập phải được xây dựng tốt và ngắn gọn về nội dung. Các tài liệu đào tạo cũng nên có ở dạng số hóa và được cài đặt thống nhất trong máy tính của học viên. Hướng dẫn sử dụng và tài liệu hướng dẫn của các thiết bị/dụng cụ mới, mô hình mới phải được dịch chính xác sang tiếng Việt và gồm những chỉ dẫn vận hành và bảo trì.

Đối với vấn đề đào tạo lại, đào tạo bổ sung cho lớp cán bộ hiện đang công tác trong ngành, các tài liệu nên được biên soạn thành các khóa đào tạo tại chức cho cán bộ kĩ thuật khí tượng thủy văn để nâng cao trình độ học vấn như sau:

- Tài liệu đào tạo năng lực chuyên môn về dự báo khí tượng thủy văn cho các cán bộ quan trắc và thiết bị tại các trạm khí tượng thủy văn những người chuyển sang làm dự báo viên. Tài liệu đào tạo nên được thiết kế cho các trình độ trung cấp, cao đẳng, đại học

- Tài liệu đào tạo cho các khóa học mới dành cho các cán bộ kĩ thuật không phải tốt nghiệp đại học/ cao đẳng chuyên ngành khí tượng thủy văn nhưng hiện đang làm việc tại các đài/trạm khí tượng thủy văn cũng như các trung tâm dự báo, quản lý quan trắc và thiết bị. Các tài liệu đào tạo nên được thiết kế để sử dụng ở các trình độ trung cấp, cao đẳng và đại học.

- Các tài liệu cung cấp hướng dẫn vận hành và bảo trì các trạm khí tượng thủy văn tự động; Các tài liệu đào tạo năng lực chuyên môn về giám sát, hiệu chỉnh và kiểm tra dữ liệu; Tài liệu cho các khóa đào tạo bổ sung về quá trình/quy trình của các máy móc/ thiết bị khí tượng thủy văn; Các tài liệu cho các khóa đào tạo bổ sung về phân tích hình ảnh ra đa.

\section{Kết luận}

Trên thế giới và ở Việt Nam hiện nay, phát triển nền kinh tế tri thức với nguồn nhân lực chất lượng cao đang là một xu thế tất yếu khách quan. Nguồn nhân lực chất lượng cao là nhân tố quyết định việc khai thác, sử dụng, bảo vệ và tái tạo các nguồn lực khác.

Trong những năm qua, cùng với sự phát triển của đất nước, ngành KTTV đã và đang được tăng cường đầu tư nhằm hướng tới mục tiêu đạt trình độ của các nước tiên tiến trong khu vực Châu Á. Phấn đấu đến năm 2025 - 2030 mạng lưới quan trắc có mật độ trạm trên diện tích lãnh thổ tương đương các nước Hàn Quốc, Nhật bản và được tự động hóa trên $90 \%$, bên cạnh đó công nghệ dự báo và hệ thống thông tin chuyên ngành được đầu tư chiều sâu, đòi hỏi phải có nguồn nhân lực thật sự có chất lượng để quản lý, khai thác có hiệu quả các hệ thống đó, tạo ra các sản phẩm, các bản tin dự báo KTTV có chất lượng cao, đáp ứng yêu cầu của xã hội, góp phần đảm bảo tăng trưởng bền vững của đất nước và giám sát biến đổi khí hậu.

Để đáp ứng sự phát triển của kỹ thuật, công nghệ trong thời kỳ mới, Tổng cục Khí tượng Thủy văn với sự quan tâm chỉ đạo của Bộ Tài nguyên và Môi trường và các Bộ, ngành, tổ chức liên quan luôn tập trung chú trọng phát triển nguồn nhân lực, đặc biệt là nguồn nhân lực chất lượng cao bằng nhiều biện pháp, chính sách có tính khả thi cao và bước đầu thu được những kết quả khả quan. Với quan điểm nhất quán coi nguồn nhân lực chất lượng cao là chìa khóa thành công của sự nghiệp hiện đại hóa và tự động hóa ngành KTTV, là cơ sở để hoàn thành các mục tiêu của Chiến lược phát triển ngành KTTV đến năm 2030 và Chiến lược Quốc gia về biến đổi khí hậu, Tổng cục Khí tượng Thủy văn sẽ tiếp tục thực hiện các giải pháp đồng bộ để phát triển nguồn nhân lực chất lượng cao một cách bền vững. 


\title{
Tài liệu tham khảo
}

1. Trần Kim Dung (2006), Quản trị nguồn nhân lực - Tp. Hồ Chí Minh: Thống kê.

2. Phạm Minh Hạc (1996), Vấn đề con ngườ trong sự nghiệp công nghiệp hóa, hiện đại hóa. NXB Chính trị Quốc gia.

3. Nghị quyết Đại hội Đảng Cộng sản Việt Nam lần thứ VIII, IX, X, XI.

4. Nguyễn Tiệp (2008), Giáo trình Nguồn nhân lực. NXB Lao động xã hội.

5. WB (2000), World Development Indicators. London: Oxford.

6. Quyết định số $03 / 2018 / \mathrm{Q}$-TTg ngày 23 tháng 01 năm 2018 của Thủ tướng Chính phủ.

7. Quyết định số 929/QĐ-TTG Phê duyệt Chiến lược phát triển ngành KTTVđến năm 2020.

8. Báo cáo Tích hợp Hệ thống và Hỗ trợ Kỹ thuật Tăng cường Hệ thống Dự báo Thời tiết và Cảnh báo sớm ở Việt Nam.

\section{CURRENT HUMAN RESOURCES AND TRAINING DEMAND FOR METEOROLOGY AND HYDROLOGY IN VIETNAM}

\section{Tran Hong Thai ${ }^{1}$}

${ }^{1}$ Viet Nam Meteorological and Hydrological Administration (VNMHA)

\begin{abstract}
Vietnam meteorology and hydrology has been being invested to reach the level of Southeast Asia and Asia level for which we need to have a complete monitoring system during 2025 - 2030, reaching level of advanced countries in the region; Forecast technology and specialized information system are deeply invested with high-quality forecasts, aiming to provide a forecast and warning system based on the impacts, contributing to ensuring sustainable growth of the country and monitoring climate change. The VNMHA considers high-quality human resources as the key to the success of the modernization and automation industry, serving as a basis for fulfilling the objectives of the Strategy for the Development of VNMHA to 2030 and the National Strategy to adapt to climate change and will continue to implement consistent guidelines to achieve the strategic goals.
\end{abstract}

Keywords: Human resource, high quality human resource, development strategy. 